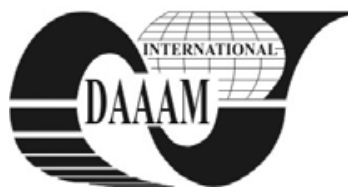

Annals of DAAAM for 2011 \& Proceedings of the 22nd International DAAAM Symposium, Volume 22, No. 1, ISSN 1726-9679 ISBN 978-3-901509-83-4, Editor B. Katalinic, Published by DAAAM International, Vienna, Austria, EU, 2011 Make Harmony between Technology and Nature, and Your Mind will Fly Free as a Bird

\title{
DEVELOPMENT OF MEASUREMENT TECHNIQUE FOR CUTTING EDGE DEFECTS IN FIBER REINFORCED PLASTICS
}

\author{
BERGER, D[ominik] \& FUERBACHER, R[oland]
}

\begin{abstract}
Most parts that are made of fiber reinforced plastics (FRP) have to be jointed to other parts. Therefore, gluing and screwing (e.g. inserts) are common technologies. In every case the machined cutting edges must be of very high quality. In every cutting test, more or less delamination and fraying is detected. Up until now there has been no standardized measuring technique to measure delamination and fraying and both of these defects are not standardized in themselves. This paper deals with these definitions and the development and definition of a measurement technique to measure both kinds of defects. This is necessary for a comparison of cutting test results with the aim of reducing these defects on machined cutting edges
\end{abstract}

Key words: measurement technique, fiber reinforced plastic, delamination, fraying

\section{INTRODUCTION}

FRP are becoming increasingly common in different fields of industry. Concerning surface quality, geometric accuracy and the ability to join parts made of FRP to other parts, the quality of machined cutting edges in FRP is of highest interest in several research activities. At the Institute of Production Engineering and Laser Technology (IFT) a new R\&D team have started to research this subject-matter.

A good quality machined cutting edge distinguishes itself by the facts that the surface shows no loose filaments reaching over the machined edge and the surface is free of interplay separations (Berger et al., 2008). For both kinds of defects (Fig. 1 ) there are no standardized or common definitions (Degischer \& Lüftl, 2009).

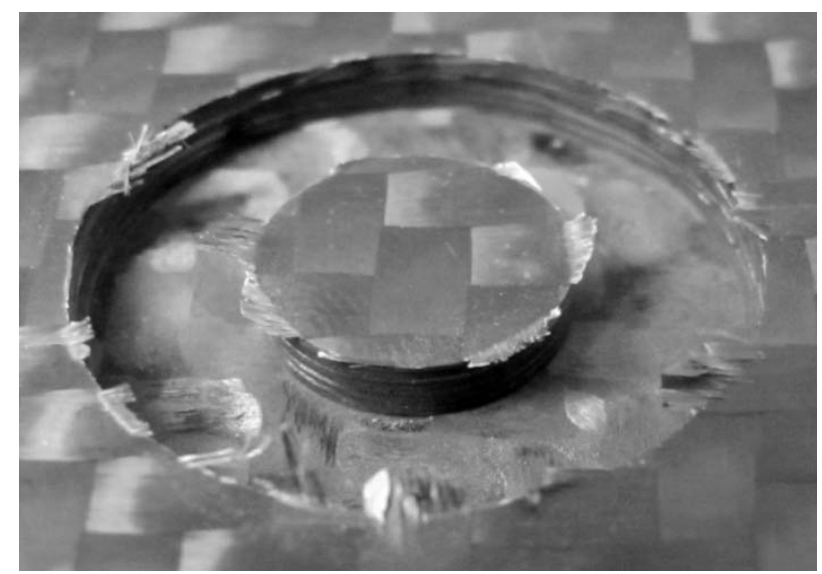

Fig. 1. Fraying and delamination

\section{DEFINITIONS}

After analyzing a lot of milled specimens in glass-, carbonand aramid-fiber-reinforced plastics, we defined the different kinds of defects as follows:
Mostly the drilling and milling process of FRP is accompanied by fraying in various magnitudes (Fig. 1). It is caused and mainly influenced by the choice of inexpedient process terms like the machining strategy, the tool, the set of machining parameters and surrounding influences. Fraying is the existence of fibers reaching over the machined edge into the drilled or milled area. Further, the length of these overlapping fibers perpendicular to the cutting edge and the length of the sub-ranges with overlapping fibers in percent of the whole cutting edge are the indicating parameters of fraying.

Delamination can be defined as the existence of-mostly interplay and mostly related to the upper and lower layersseparation of material next to the cutting edge opposite to the milled or drilled area. Further, we defined that delaminated areas always lie above the unmachined material surface. Therefore, e.g. chunking is not defined as delamination. Delaminated areas must still be connected to the material and must not be defined as fraying. Sometimes the delamination of single strands occurs but usually a delamination of filaments can be noticed (Sheikh-Ahmad, 2009).

Fraying and delamination can be the cause of each other and therefore can often be observed together in a single area although the two also can appear independently. This circumstance makes it necessary to develop different measurement techniques and assessment systems for fraying and delamination.

\section{FRAYING}

To measure the fraying of drilled or milled geometries, an optical microscope is required. The equipment must allow a magnification of at least $20 x, 40 x$ or higher is highly recommended. For this purpose - after several tests with different optical microscopes - the optical, automated CNC measurement device "Nikon Nexiv VMR 3020" with a maximum magnification of $128 \mathrm{x}$ was used at the IFT.

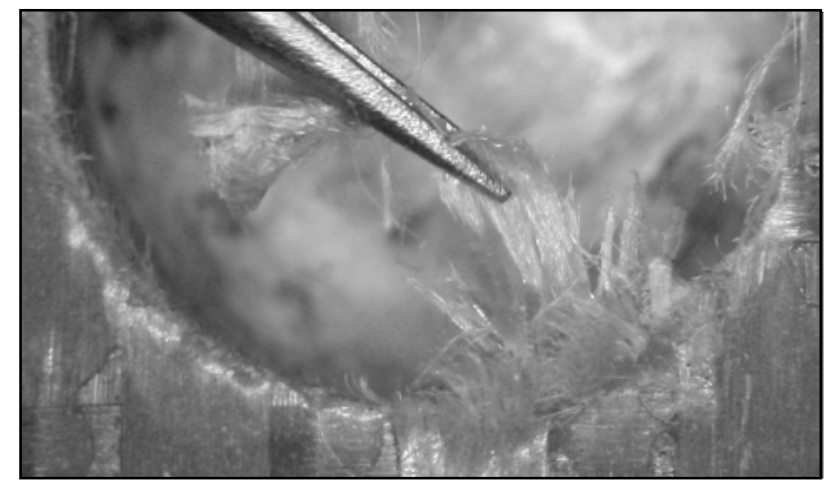

Fig. 2. Stretched texture

We defined that only the length of those sub-ranges have to be measured and summed up, which show a length of overlapping fibers of more than $1 \%$ of the reference diameter 
(e.g. tool diameter or radial cutting depth). After measuring, the relative proportion of the summed areas on the circumference of the geometry has to be set for the assessment.

To determine the absolute fraying-length of the overlapping fibers, the longest fiber of each sub-range has to be stretched carefully; a pair of small pointed precision-forceps can be used (Fig. 2). Then the length of the longest fiber has to be measured perpendicular to the cutting edge.

In Table 1 the assessment pattern is shown for the fraying of FRP. As previously mentioned, the diameter or the radial cutting depth of the tool affects the maximum length of fraying and the relative maximum is the longest measured overlapping fiber in percentage of the maximum length.

\begin{tabular}{|c|ccccc|}
\hline \multirow{2}{*}{$\begin{array}{c}\text { Relative } \\
\text { maximum }\end{array}$} & $>0 \%$ & $>1 \%$ & $\ldots$ & $>32 \%$ & $>56 \%$ \\
& $\leq 1 \%$ & $\leq 2 \%$ & $\cdots$ & $\leq 56 \%$ & $\leq 100 \%$ \\
\hline$>0 \%, \leq 1 \%$ & 99 & 98 & $\cdots$ & 92 & 91 \\
$>1 \%, \leq 2 \%$ & 89 & $\vdots$ & $\ldots$ & $\vdots$ & 81 \\
$\vdots$ & $\vdots$ & $\vdots$ & $\ldots$ & $\vdots$ & $\vdots$ \\
$>32 \%, \leq 56 \%$ & 29 & $\vdots$ & $\ldots$ & $\vdots$ & 21 \\
$>56 \%, \leq 100 \%$ & 19 & 18 & $\ldots$ & 12 & 11 \\
\hline
\end{tabular}

Tab. 1. Assessment pattern for fraying quality index (FQI)

The assessment system, FQI, is related to the international coding after the IP code. The result of the assessment provides a two-digit number where each of the digits describes a certain parameter. Each parameter can assume the number one to nine and these nine categories are related to the Renard preferred values (DIN 323). The first digit, e.g., the digit 1 of FQI "19", describes the maximum length of the longest overlapping fiber perpendicular to the cutting edge. If using the full width of a milling cutter with a diameter of $6 \mathrm{~mm}$, the longest fiber would have a length of 4.5 to $6 \mathrm{~mm}$. The second digit, 9, signifies that the summed length of the sub-ranges showing fraying is below $1 \%$ of the whole cutting edge length.

The example of a ring flute milled in carbon-fiberreinforced material shown in Fig. 1 reaches a FQI of "22" as well for the inner as the outer circle. So this example is quite next the worst FQI of " 11 " and far from the best FQI of " 99 ".

The general idea of this evaluation system is to use it both for defining the required quality of the cutting edge before the drilling/milling process as well as for the evaluation and comparison of already machined cutting edges. Furthermore, it should be used similar to the code for surface properties on workshop drawings.

\section{DELAMINATION}

As defined above, delamination indicates areas of the specimen which lie above the unmachined surface. To assure that delamination is not confused with the surface roughness we additionally defined that only these areas which lie at least half of the surface roughness amplitude parameter $\mathrm{R}_{\mathrm{t}}$ (maximum height of the profile) above the mean line of the roughness profile are measured.

Fig. 3 shows the three steps of the developed measurement process for the determination of delamination. First, a 3Dpicture is taken, shown in section one, with the "Alicona Infinite Focus”, an optical 3D micro coordinate measurement machine. This set of values includes the height measured value for each dot with an accuracy of up to $10 \mathrm{~nm}$. To define the mean layer concerning surface roughness it is recommended to mark at least ten points. Using these points, the mean layer is calculated by the software and further used as the zero-layer to calculate delamination. Furthermore, a profile including no delamination shall be defined to determine the roughness parameters.
Second, to get comparable results a standard range has to be set, as can be seen in section two. According to the definition of delamination, the area within the cutting edge has been cut out. Furthermore, the outer area has to be limited to half of the tool diameter. In the case of delamination this outer limitation is not corresponding with the radial cutting depth. This limitation is necessary to assure that the area of delamination is always referenced to the same basic surface. When machining inside the specimen the whole circumference-area has to be limited.



Fig. 3. Measurement process (steps from left to right)

After taking the 3D picture and cutting out unnecessary areas a so-called depth image (in color) can be created as the third step. Using the Alicona software, pixels below a certain level - in this case the middle line of surface roughness - can be faded out. In section three of Fig. 3 this effect is shown. As the next step, a frequency distribution of the height values is done for the whole remaining surface (all not cut or faded out pixels). The class range therefore is set to the value of $40 \mu \mathrm{m}$. The lower limit of the first class is set to half of the surface roughness amplitude parameter $\mathrm{R}_{\mathrm{t}}$. When there are less than $0.1 \%$ of pixels in a class no further class will be set and measured.

The assessment of delamination will be done in the same way like the assessment of fraying. The first digit of the delamination quality index (DQI) will provide the information of the maximum delamination height and the second digit will provide the information about the delaminated area.

\section{CONCLUSION}

The defined measurement techniques and assessment systems developed at the IFT enables researchers and users to define the required quality of the cutting edge in FRP and to compare results.

This analysis and development has been tested in several cutting tests with numerous different milling cutters and drill bits in glass-, carbon- and aramid-fiber reinforced plastics. The mentioned assessment systems will be used at the IFT for the next number of years in all research activities concerning FRP and shall be disseminated into academia and industry.

\section{REFERENCES}

Berger, D.; Bleicher, F.; Dorn, C.; Puschitz, F. (2008). DAAAM International Scientific Book 2008, DAAAM International Vienna, 978-3-901509-66-7, Vienna

Degischer, H.P.; Lüftl, S. (2009). Leichtbau: Prinzipien, Werkstoffauswahl und Fertigungsverfahren, WILEY-VCH, 978-3527323722, Weinheim

Sheikh-Ahmad Jamal Y. (2009). Machining of Polymer Composites, Springer Science+Business Media, 978-0-38735539-9, Abu Dhabi

*** (2011) http://www.alicona.com - InfiniteFocus for form and roughness measurement, Accessed on 2011-08-22

*** (2011) http://www.nikoninstruments.com - A high resolution lens system featuring large $300 \mathrm{~mm}$ range and laser height measurements, Accessed on 2011-08-22 